\title{
High Sensitivity of Thymocytes of LEC Strain Rats to Induction of Apoptosis by X-Irradiation
}

\author{
Masanobu HAYASHI ${ }^{1)}$, Aogu NAGATA ${ }^{1)}$, Daiji ENDOH ${ }^{1)}$, Jiro ARIKAWA ${ }^{2)}$ and Toyo OKUI ${ }^{3)}$ \\ ${ }^{1)}$ Department of Veterinary Radiology, School of Veterinary Medicine, Rakuno Gakuen University, Ebetsu 069-8501, ${ }^{2)}$ Institute for \\ Animal Experimentation, School of Medicine, Hokkaido University, Sapporo 060-8638 and ${ }^{3) H o k k a i d o ~ I n s t i t u t e ~ o f ~ P u b l i c ~ H e a l t h, ~}$ \\ Sapporo 060-0819, Japan
}

(Received 3 December 2001/Accepted 22 March 2002)

\begin{abstract}
It is known that physical disruption of cell contacts induces apoptosis of thymocytes. When thymocytes from LEC and WKAH rats were incubated in vitro at $37^{\circ} \mathrm{C}$ for $0-6 \mathrm{hr}$ and then the proportion of apoptotic cells was determined using a flow cytometer, it was found that the percentages of apoptotic thymocytes from both LEC and WKAH rats increased with incubation time and that the proportion of apoptotic cells from LEC rats was significantly higher than that from WKAH rats at each incubation time. The fact that cycloheximide, an inhibitor of protein synthesis, did not show significant inhibitory effects on induction of apoptosis of thymocytes indicates that induction of apoptosis during in vitro cultivation did not require de novo protein synthesis. When thymocytes from LEC and WKAH rats were X-irradiated in vitro at 4 and $8 \mathrm{~Gy}$, the percentages of radiation-induced apoptotic cells increased with post-incubation time after X-irradiation in both LEC and WKAH rat thymocytes and the proportions of apoptotic cells from LEC rats were significa ntly higher than those from WKAH rat cells at 2 and $4 \mathrm{hr}$ post-incubation after X-irradiation. When thymocytes from LEC and WKAH rats were $\mathrm{X}$-irradiated in the presence of cycloheximide, the induction of apoptosis was substantially inhibited, indicating that radiationinduced apoptosis of thymocytes from LEC and WKAH rats required de novo protein synthesis. The present results showed high sensitivities of thymocytes of LEC rats to induction of apoptosis during in vitro cultivation and by $\mathrm{X}$-irradiation.
\end{abstract}

KEY WORDS: apoptosis, LEC strain rat, protein synthesis, thymocyte, $\mathrm{X}$-irradiation.

J. Vet. Med. Sci. 64(7): 597-601, 2002

Apoptosis, or programmed cell death, plays a major role in the development, tissue homeostasis, and elimination of damaged cells. This mode of cell death is characterized morphologically by cell shrinkage, chromatin condensation, membrane blebbing and formation of apoptotic bodies [29] and biochemically by internucleosomal fragmentation of DNA [28]. Apoptosis occurs in response to a diversity of physiological or pathological stimuli and to treatment of cells with various chemical and physical agents such as ionizing radiation. Thymocytes are highly radiosensitive and undergo apoptosis within a few hours after X-irradiation at low doses $[3,16,22,30]$. Apoptosis induced by X-irradiation requires de novo protein synthesis [22], and the tumor suppressor p53 has been shown to regulate this type of apoptosis in thymocytes $[5,12]$. However, ionizing radiation can induce apoptosis in thymocytes via p53-independent mechanisms [5, 23]. Furthermore, apoptosis is induced more readily in thymocytes by other types of stimuli such as heat shock. It has been reported that heat-induced apoptosis is correlated with activation of mitogen-activated protein kinases such as p38mapk and stress-activated protein kinase/c-Jun N-terminal kinase (SAPK/JNK) [14] and that induction of apoptosis by heat treatment of thymocytes does not require de novo protein synthesis [22].

Radiation has been shown to cause cell death by inducing apoptosis in sensitive target cells, and radiation-induced apoptosis may play a role in killing of tumor cells in radiotherapy. However, normal tissue damage also occurs by radiation in radiotherapy. Individual variation in the level of normal tissue damage resulting from radiotherapy has been observed in clinics $[25,26]$. Part of this variation is genetically predetermined, since there are several syndromes in humans such as ataxia telangiectasia with enhanced sensitivity to ionizing radiation [19, 24]. However, in the absence of a clinical, heritable disorder, no naturally occurring genetic polymorphisms that influence susceptibility to radiation-induced damage to normal tissue in humans have been identified. Therefore, animal models would be useful for understanding the correlation between susceptibility to radiation-induced apoptosis and radiation sensitivity of normal tissue damage in radiotherapy.

The LEC rat strain was established at the Center for Experimental Plants and Animals, Hokkaido University [21, 33]. Rats of this strain suffer from spontaneous fulminant hepatitis associated with severe jaundice at about 4 months of age. Other characteristics of LEC rats are a high incidence of spontaneous liver cancer in long-surviving individuals [33] and an increased sensitivity in vivo and in vitro to ionizing radiation [9]. In our previous studies using colonyforming assay for determination of cell survival, we found that primary fibroblasts and fibroblast cell lines from LEC rats were more sensitive to $\mathrm{X}$-irradiation, but not to ultraviolet radiation in the short wavelength (ultraviolet $\mathrm{C}, \mathrm{UVC}$ ), than were cells from a control strain of WKAH rats [9-11, 17]. On the other hand, LEC rat cells showed a higher sensitivity to induction of apoptosis by UVC radiation, but not $\mathrm{X}$-irradiation [9-11]. Therefore, the effects of $\mathrm{X}$-irradiation on induction of apoptosis in LEC rat cells are still not clear. In the present study, we found high sensitivities of thymocytes of LEC rats to induction of apoptosis during in 
vitro cultivation and by $\mathrm{X}$-irradiation.

\section{MATERIALS AND METHODS}

Rats: Inbred strains of LEC/Hkm (LEC) and WKAH/ $\mathrm{Hkm}$ (WKAH) male rats were cared for according to the principles of the 'Guide for the Care and Use of Laboratory Animals' prepared by Rakuno Gakuen University. WKAH rats were used as controls in the present study. All rats were maintained under conditions described previously [9].

Isolation of thymocytes and culture: Thymocytes were prepared from 4-week-old rats essentially as described by Ohyama et al. [16]. Briefly, single-cell suspensions were prepared by pressing the thymus through wire mesh screens followed by two passages through a 25 -gauge needle. The cells were resuspended in RPMI 1640 medium containing $10 \%$ fetal calf serum. The cell cultures were kept at ambient humidity and $37^{\circ} \mathrm{C}$ in an atmosphere containing $5 \% \mathrm{CO}_{2}$.

$X$-irradiation: $\mathrm{X}$-irradiation was carried out utilizing a Hitachi MBR-1520R X-ray generator operating at $150 \mathrm{kV}$ and $15 \mathrm{~mA}$ with a $0.5 \mathrm{~mm}-\mathrm{Cu}+1.0 \mathrm{~mm}-\mathrm{Al}$ filter at a dose rate of $0.95 \mathrm{~Gy} / \mathrm{min}$.

Reagent: Cycloheximide (Sigma Aldrich Chemical Co.) was dissolved in dimethyl sulfoxide (DMSO). DMSO efficiently scavenges reactive oxygen species such as hydroxyl radicals produced by $\mathrm{X}$-irradiation. To prevent DMSO from affecting radiation-induced apoptosis, final concentrations of DMSO in the medium were equal in control and cycloheximide-treated cell populations, and were $<0.5 \%$. The cells were exposed to cycloheximide at $37^{\circ} \mathrm{C}$ for $1 \mathrm{hr}, \mathrm{X}$ irradiated, and then incubated at $37^{\circ} \mathrm{C}$ in the presence of cycloheximide.

Flow cytometry: The apoptotic cells were labeled with fluorescein-dUTP by using a Mebstain apoptosis kit direct (Medical \& Biological Laboratories Co.) according to the manufacturer's instructions. Briefly, X-irradiated cells $(1 \times$ $10^{6}$ ) were incubated in the medium at $37^{\circ} \mathrm{C}$ for $0-6 \mathrm{hr}$ and collected. The cells were washed several times with PBS containing $0.2 \% \mathrm{BSA}$. The cells were fixed with $0.1 \mathrm{M}$ $\mathrm{NaH}_{2} \mathrm{PO}_{4}$ containing $4 \%$ paraformaldehyde at $4{ }^{\circ} \mathrm{C}$ for 30 min, washed 2 times with PBS containing $0.2 \%$ BSA, and then pelleted by centrifugation at $500 \times \mathrm{g}$. The cells were fixed in $5 \mathrm{ml}$ of cold $70 \%$ ethanol for $30 \mathrm{~min}$ at room temperature and stored at $-20^{\circ} \mathrm{C}$. Just prior to flow cytometric analysis, individual samples were labeled with fluoresceindUTP. Fluorescence was measured with a Coulter EPICS EL flow cytometer using a 530-nm filter. The percentage of apoptotic cells was determined using multicycle software.

Statistical analysis: All data are expressed as means \pm standard deviations. Differences between means were analyzed statistically by Student's $t$-test. Values of $p<0.05$ and $p<0.01$ were considered significant.

\section{RESULTS}

Since it is known that physical disruption of cell contacts induces apoptosis of thymocytes, we examined induction of

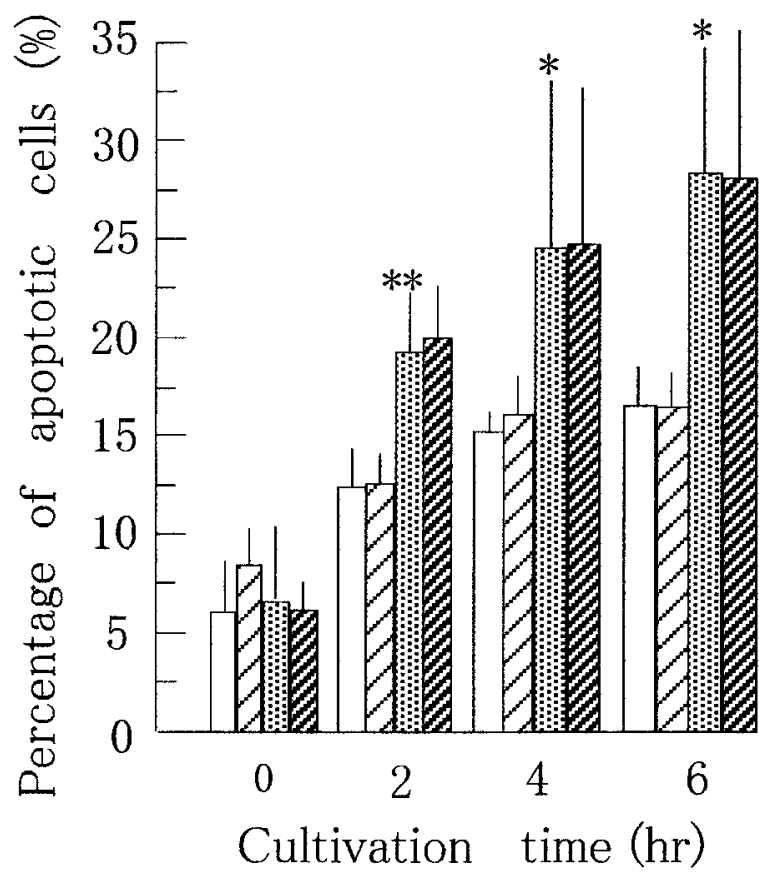

Fig. 1. Induction of apoptosis in thymocytes from LEC and WKAH rats during in vitro cultivation. Thymocytes were prepared from LEC (再, and WKAH $(\square$, , rats and incubated at $37^{\circ} \mathrm{C}$ for $0-6 \mathrm{hr}$ in the absence $(\square$, , ij) and presence (四, 四) of $12.5 \mu \mathrm{g} / \mathrm{m} l$ cycloheximide, and then the number of apoptotic cells was counted using a flow cytometer at each incubation time. Each value represents the average from four separate experiments. Error bars represent the standard deviations of mean values. $* p<0.05$, ** $p<0.01$, compared with the values obtained in WKAH rat cells by means of Student's $t$ test.

apoptosis of thymocytes from LEC and WKAH rats during in vitro cultivation (Fig. 1). When thymocytes from LEC and WKAH rats were incubated in vitro at $37^{\circ} \mathrm{C}$ for $0-6 \mathrm{hr}$ and then the proportion of apoptotic cells was determined using a flow cytometer, it was found that the percentages of apoptotic thymocytes from both LEC and WKAH rats increased with incubation time and that the proportion of apoptotic cells from LEC rats was significantly higher than that from WKAH rats at each incubation time. To examine whether induction of apoptosis during in vitro cultivation requires de novo protein synthesis, thymocytes were incubated in the presence of cycloheximide, an inhibitor of protein synthesis, at concentrations of 5 to $50 \mu \mathrm{g} / \mathrm{ml}$. No significant difference was observed between the percentages of apoptotic cells from either LEC or WKAH rats cultivated in the presence of $12.5 \mu \mathrm{g} / \mathrm{m} l$ of cycloheximide and those cultivated in the absence of cycloheximide (Fig. 1). Cycloheximide did not show significant inhibitory effects on induction of apoptosis of thymocytes during in vitro cultivation at a concentration of $50 \mu \mathrm{g} / \mathrm{m} l$ (data not shown).

When thymocytes from LEC and WKAH rats were Xirradiated in vitro at 4 and $8 \mathrm{~Gy}$, the percentages of apoptotic 


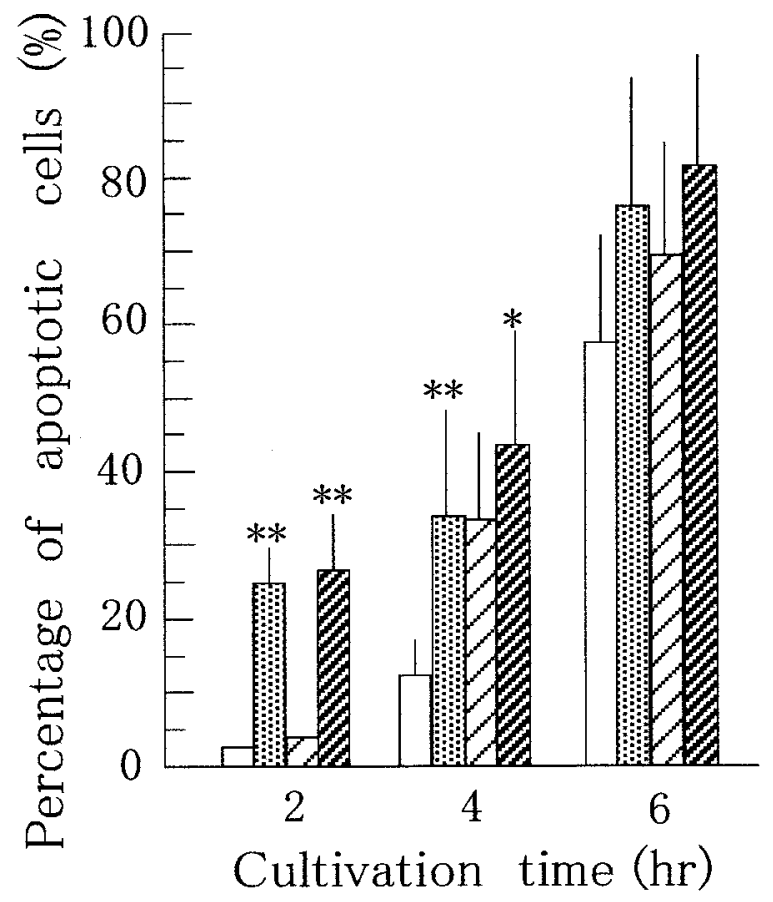

Fig. 2. Induction of apoptosis in LEC and WKAH rat cells after X-irradiation. After LEC ( had been exposed to 4 ( $\square$, and 8 ) Gy of X-rays, the cells were incubated at $37^{\circ} \mathrm{C}$ for $0-6 \mathrm{hr}$, and the number of apoptotic cells was counted using a flow cytometer at each incubation time. Percentage of radiation-induced apoptotic cells $=[$ (number of apoptotic cells in the $\mathrm{X}$-irradiated cell population - number of apoptotic cells in the unirradiated cell population)/(number of total cells - number of apoptotic cells in the unirradiated cell population) $] \times 100(\%)$. Error bars represent the standard deviations of mean values $(\mathrm{n}=4) . * p<0.05$, ** $p<0.01$, compared with the values obtained in WKAH rat cells by means of Student's $t$-test.

cells increased with post-incubation time after X-irradiation in both LEC and WKAH rat thymocytes, and the proportions of apoptotic cells from LEC rats were significantly higher than those from WKAH rats at 2 and $4 \mathrm{hr}$ post-incubation after X-irradiation (Fig. 2). At $2 \mathrm{hr}$ post-incubation after irradiation, the proportion of apoptotic cells from LEC rats was 7- to 8-fold higher than that from WKAH rats. At $6 \mathrm{hr}$ post-incubation after irradiation, no significant difference was observed between the proportions of apoptotic cells in LEC and WKAH rat cell populations.

When thymocytes from LEC and WKAH rats were Xirradiated at $4 \mathrm{~Gy}$ in the presence of cycloheximide, the induction of apoptosis was substantially inhibited (Fig. 3). In the case of WKAH rat cells, cycloheximide completely inhibited radiation-induced apoptosis at a concentration of 5 $\mu \mathrm{g} / \mathrm{m} l$. In thymocytes of LEC rats, approximately $70 \%$ of induction of apoptosis was inhibited by treatment with cycloheximide at a concentration of $5 \mu \mathrm{g} / \mathrm{ml}$, and radiationinduced apoptosis was inhibited by cycloheximide in a

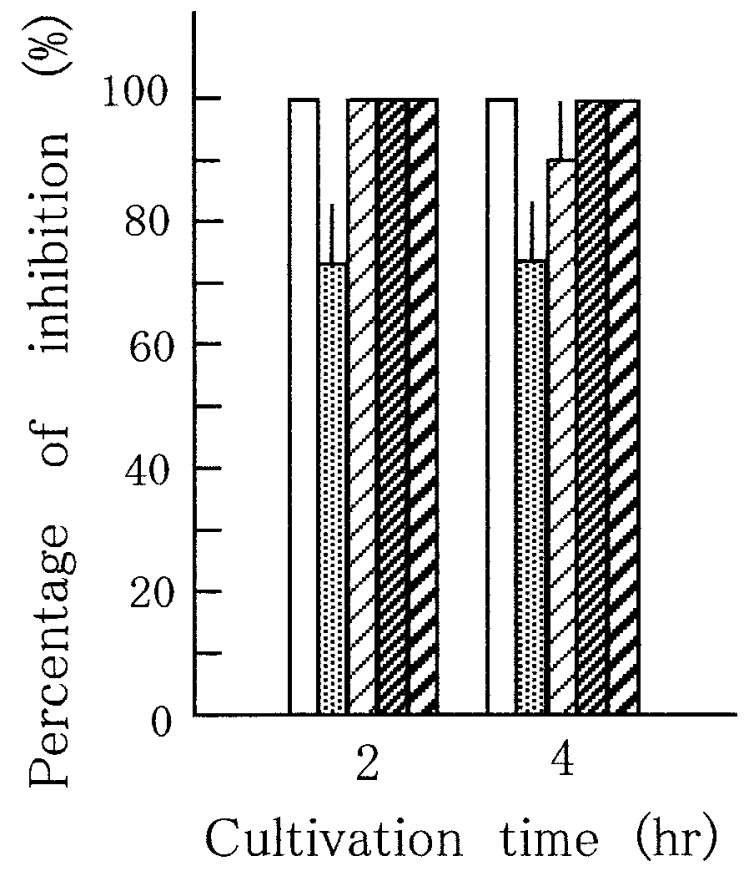

Fig. 3. Effects of cycloheximide on radiation-induced apoptosis in LEC and WKAH rat cells. After WKAH ( $\square$ ) and LEC (间, 圂, rat cells had been exposed to 4 Gy of X-rays in the absence and presence of cycloheximide at $\quad \square$ ( 19 ), 12.5

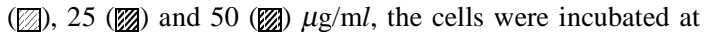
$37^{\circ} \mathrm{C}$ for $0-6 \mathrm{hr}$, and the number of apoptotic cells was counted using a flow cytometer at each incubation time. Percentage of inhibition $=[1-($ number of radiation-induced apoptotic cells that had been treated with cycloheximide/ number of radiation-induced apoptotic cells that had not been treated with cycloheximide) $] \times 100(\%)$. Error bars represent the standard deviations of mean values $(n=4)$.

dose-dependent manner. Similar inhibitory effects by cycloheximide on induction of apoptosis were observed in 8-Gy-irradiated thymocytes from LEC and WKAH rats (data not shown).

\section{DISCUSSION}

Lymphoid tissues such as the thymus, spleen and lymph nodes are known to be extremely sensitive to ionizing radiation [reviewed in 13]. In our previous studies using colony-forming assay to determine cell survival, we found that fibroblasts from LEC rats were more sensitive to X-irradiation than were cells from WKAH rats $[9,17]$. On the other hand, no significant difference was found in induction of apoptosis of LEC and WKAH rat fibroblasts by X-irradiation [10]. The present results showed that LEC rat thymocytes were more sensitive to induction of apoptosis by $\mathrm{X}$ irradiation than were WKAH rat cells and that apoptosis was induced at an earlier incubation time after X-irradiation in LEC rat thymocytes than in WKAH rat thymocytes. The fact that cycloheximide substantially inhibited radiation- 
induced apoptosis indicates that the induction of apoptosis required de novo protein synthesis in both LEC and WKAH rat thymocytes. Requirement of de novo protein synthesis in radiation-induced apoptosis in rat thymocytes is in good agreement with results reported by Sellins and Cohen [22]. It is thought that ionizing radiation produces reactive oxygen species (ROS) and that DNA damage produced by ROS activates the pathway of apoptosis in thymocytes. Although ionizing radiation produces a variety of lesions in DNA, double-strand breaks (DSBs) seem to be most responsible for radiation-induced cell death $[15,20]$. We have shown that the increased radiosensitivity of LEC rat cells is due to a reduced level of repair of DSBs. However, Beitez-Bribiesca and Sanchez-Suarez [4] suggest that the presence of DSBs is not directly associated with induction of apoptotic cell death of rat thymocytes. Therefore, it is not clear whether a deficiency in repair of DSBs is correlated with the high sensitivity of radiation-induced apoptosis in LEC rat thymocytes. Recently, the locus of the main gene responsible for high radiosensitivity in LEC rat cells has been assigned to the rat chromosome 4 [1]. A linkage study of deficiency in repair of DSBs to the high sensitivity of radiation-induced apoptosis in LEC rat thymocytes is now in progress. We have also reported that LEC rat cells show an abnormality of transient cell cycle arrests that occur in normal rat cells following ionizing radiation $[7,8,10]$. Since it is well known that a regulatory pathway of cell cycle progression is associated with induction of apoptosis [12, 23, 32 ], abnormality of transient cell cycle arrests may be associated with the high sensitivity of radiation-induced apoptosis in LEC rat cells.

Apoptosis of thymocytes is induced by various stimuli other than ionizing radiation, such as glucocorticoids, heat shock, antibodies, $\mathrm{Ca}^{2+}$ ionophores, and toxins [6]. It has been shown that after physical disruption of cell contacts, apoptosis of thymocytes is induced during in vitro cultivation [27]. The present study showed that apoptosis of thymocytes from both LEC and WKAH rats was induced during in vitro cultivation and that the proportion of apoptotic cells from LEC rats was significantly higher than that from WKAH rats at each incubation time. The fact that cycloheximide did not show significant inhibitory effects on induction of apoptosis during in vitro cultivation indicates that induction of apoptosis during in vitro cultivation did not require de novo protein synthesis. The mechanism of induction of apoptosis of rat thymocytes without de novo protein synthesis during in vitro cultivation remains unclear at this time. It has been suggested that ROS is a mediator of thymocyte apoptosis induced by in vitro cultivation [27]. Although ionizing radiation also generates ROS, radiationinduced apoptosis required de novo protein synthesis in rat thymocytes, but apoptosis by in vitro cultivation did not. In the case of in vitro cultivation, the production of ROS in thymocytes is likely to originate mainly from mitochondria [27]. On the other hand, ionizing radiation induces apoptosis via nuclear DNA damage. Therefore, pathways of apoptosis activated by ionizing radiation may be different from those by in vitro cultivation, although induction of apoptosis of thymocytes by both treatments is mediated by ROS. Furthermore, LEC rat thymocytes showed a high sensitivity in induction of apoptosis by both pathways. Since it has been shown that LEC rats have a defect in T cell maturation $[2,31]$, the difference in the thymocyte subpopulations of LEC and WKAH rats may be associated with the different sensitivity of induction of apoptosis during in vitro cultivation.

It has been reported that LEC rat fibroblasts show a high sensitivity in reproductive cell death but not in induction of apoptosis to X-irradiation $[9,10]$. On the other hand, in the present study, LEC rat thymocytes showed a high sensitivity to induction of apoptosis by X-irradiation. Thus, the LEC rat is a useful animal model for understanding the correlation between susceptibility to radiation-induced apoptosis and radiation sensitivity of normal tissue damage in radiotherapy.

ACKNOWLEDGEMENT. This work was supported in part by a Grant-in-Aid from the Ministry of Education, Science, Sports and Culture of Japan.

\section{REFERENCES}

1. Agui, T., Miyamoto, T., Jung, C. G., Tsumagari, T., Masuda, K. and Manabe, T. 2000. Genetic linkage analysis of X-ray hypersensitivity in the LEC mutant rat. Mamm. Genome 11: $862-865$.

2. Agui, T., Oka, M., Yamada, T., Sasaki, T., Izumi, K., Himeno, K. and Matsumoto, K. 1990. Maturation arrest from $\mathrm{CD} 4^{+} \mathrm{CD}^{+}$to $\mathrm{CD}^{+} 8^{-}$thymocytes in a mutant strain (LEC) of rat. J. Exp. Med. 172: 1615-1624.

3. Allan, D. J. and Harmon, B. V. 1986. The morphological characterization of cell death induced by mild hyperthermia and comparison with death induced by mild hyperthermia and comparison with death induced by ionizing radiation and cytotoxic drugs. Scanning Electron Microsc. 3: 1121-1133.

4. Beitez-Bribiesca, L. and Sanchez-Suarez, P. 1999. Oxidative damage, bleomycin, and gamma radiation induced different types of DNA strand breaks in normal lymphocytes and thymocytes. Ann. New York Acad. Sci. 887: 133-149.

5. Clarke, A. R., Purdie, C. A., Harrison, D. J., Morris, R. G., Bird, C. C., Hopper, M. L. and Wyllie, A. H. 1993. Thymocyte apoptosis induced by p53-dependent and independent pathways. Nature (Lond.) 362: 849-852.

6. Dyson, J. E. D., Simmons, D. M., Daniel, J., McLaughlin, J. M., Quirke, P. and Bird, C. C. 1986. Kinetics and physical studies of cell death induced by chemotherapeutic agents or hyperthermia. Cell Tissue Kinet. 19: 311-324.

7. Hayashi, M., Ishimori, K., Maeda, A., Watanabe, T., Arai, S. and Okui, T. 1996. Radioresistant DNA synthesis in fibroblast cell lines derived from LEC strain rats. Mutat. Res. 352: 117121.

8. Hayashi, M., Kuzumi, T., Arai, S. and Okui, T. 1999. Abnormal accumulation of G2/M-phase cells from LEC strain rats after X-irradiation at S-phase. J. Vet. Med. Sci. 61: 975-978.

9. Hayashi, M., Okui, T., Endoh, D., Sato, F., Kasai, N. and Namioka, S. 1994. Radiation-hypersensitivity of LEC strain rats controlled by a single autosomal recessive gene. Mutat. 
Res. 314: 135-142.

10. Hayashi, M., Uehara, K., Kirisawa, R., Endoh, D., Arai, S. and Okui, T. 1997. Abnormal G1 arrest in the cell lines from LEC strain rats after X-irradiation. J. Vet. Med. Sci. 59: 769-773.

11. Hayashi, M., Uehara, K., Ichikawa, Y., Arai, S., Isogai, E. and Okui, T. 1998. Higher sensitivity in induction of apoptosis in fibroblast cell lines derived from LEC strain rats to UV-irradiation. J. Vet. Med. Sci. 60: 207-212.

12. Lowe, S. W., Schmitt, E. M., Smith, S. W., Osborne, B. A. and Jacks, T. 1993. p53 is required for radiation-induced apoptosis in mouse thymocytes. Nature (Lond.) 362: 847-849.

13. Maruyama, Y. and Feola, J. M. 1987. Relative radiosensitivities of the thymus, spleen, and lymphohemopoietic systems. Adv. Radiat. Biol. 12: 1-82.

14. Mosser, D. D., Caron, A. W., Bourget, L., Denis-Larose, C. and Massie, B. 1997. Role of the human heat shock protein hsp 70 in protection against stress-induced apoptosis. Mol. Cell. Biol. 17: 5317-5327.

15. Murray, D., Simpson, R., Rosenberg, E., Carraway, A. and Britten, R. 1994. Correlation between gamma-ray-induced DNA double-strand breakage and cell killing after biologically relevant doses: analysis by pulse-field gel electrophoresis. Int. J. Radiat. Biol. 65: 419-426.

16. Ohyama, H., Yamada, T., Ohkawa, A. and Watanabe, I. 1985. Radiation-induced formation of apoptotic bodies in rat thymus. Radiat. Res. 101: 123-130.

17. Okui, T., Endoh, D., Arai, S., Isogai, E. and Hayashi, M. 1996. Cross-sensitivity of X-ray-hypersensitive cells derived from LEC strain rats to DNA-damaging agents. J. Vet. Med. Sci. 58: 1067-1071.

18. Okui, T., Endoh, D. and Hayashi, M. 1999. Deficiency in fast repair process of potentially lethal damage induced by X-irradiation in fibroblasts derived from LEC strain rats. Mutat. Res. 435: $81-88$.

19. Paterson, M. C. and Smith, P. J. 1979. Ataxia-telangiectasia: an inherited human disorder involving hypersensitivity to ionizing radiation and related DNA-damaging chemicals. Annu. Rev. Genet. 13: 291-318.

20. Radford, I. R. 1986. Evidence for a general relationship between the induced level of DNA double-strand breakage and cell-killing after X-irradiation of mammalian cells. Int. J. Radiat. Biol. 49: 611-620.

21. Sasaki, M., Yoshida, M. C., Kagamori, K., Takeichi, N., Koba- yashi, H., Dempo, K. and Mori, M. 1985. Spontaneous hepatitis in an inbred strain of Long-Evans rats. Rat News Lett. 14: 46 .

22. Sellins, K. S. and Cohen, J. J. 1991. Hyperthermia induces apoptosis in thymocytes. Radiat. Res. 126: 88-95.

23. Strasser, A., Harris, A. W., Jacks, T. and Cory, S. 1994. DNA damage can induce apoptosis in proliferating lymphoid cells via p53-independent mechanisms inhibitable by Bcl-2. Cell 79: 329-339.

24. Taylor, A. R. M., Harnden, D. G., Arlett, C. F., Harcourt, S. A., Lehman, A. R., Stevens, S. and Bridges, B. A. 1979. Ataxia telangiectasia: a human mutation with abnormal radiation sensitivity. Nature (Lond.) 258: 427-429.

25. Tucker, S. L., Turesson, I. and Thames, H. D. 1992. Evidence for individual differences in the radiosensitivity of human skin. Eur. J. Cancer 28A: 1783-1791.

26. Turesson, I. 1990. Individual variation and dose dependency in the progression rate of skin telangiectasia. Int. J. Radiat. Oncol. Biol. Phys. 19: 1569-1574.

27. Wang, J.-F., Jerrells, T. R. and Spitzer, J. J. 1996. Decreased production of reactive oxygen intermediates is an early event during in vitro apoptosis of rat thymocytes. Free Radical Med. 20: $533-542$.

28. Wyllie, A. H. 1980. Glucocorticoid-induced thymocyte apoptosis is associated with endogenous endonuclease activation. Nature (Lond.) 284: 555-556.

29. Wyllie, A. H., Kerr, J. F. R. and Currie, A. R. 1980. Cell death: The significance of apoptosis. Int. Rev. Cytol. 68: 251-306.

30. Yamada, T. and Ohyama, H. 1988. Radiation-induced interphase death of rat thymocytes is internally programmed (apoptosis). Int. J. Radat. Biol. 53: 65-75.

31. Yamada, T., Natori, T., Izumi, K., Sasaki, T., Agui, T. and Matsumoto, K. 1991. Inheritance of T helper immunodeficiency (thid) in LEC mutant rats. Immunogenetics 33: 216219.

32. Yonish-Rouach, E., Grunwald, D., Wilder, S., Kimchi, A., May, E., Lawrence, J.-J., May, P. and Oren, P. 1993. p 53mediated cell death: relationship to cell cycle control. Mol. Cell. Biol. 13: 1415-1423.

33. Yoshida, M. C., Masuda, R., Sasaki, M., Takeichi, N., Kobayashi, H., Dempo, K. and Mori, M. 1987. New mutation causing hereditary hepatitis in the laboratory rat. J. Hered. 78: 361365. 